Original Research Article

\title{
Vitamin D - A Nutrient out to make its multifaceted presence felt
}

Sharma, Sheel

Department of Biochemistry and Human Nutrition, Banasthali Vidyapith, Banasthali, Rajasthan

Corresponding Author: sssheels@gmail.com

\section{A R T I C L E I N F O}

Received: 05 February 2018 | Accepted: 22 April 2018 | Published Online: 15 August 2018

DOI: $10.31786 / 09756272.18 .9 .1 .124$

EOI: $10.11208 /$ essence.18.9.1.124

Article is an Open Access Publication.

This work is licensed under Attribution-Non Commercial 4.0 International

(https://creativecommons.org/licenses/by/4.0/)

CThe Authors (2018). Publishing Rights @ MANU_ICMANU \& ESSENCE-IJERC.

\section{A B S T R A C T}

Vitamin D deficiency (VDD) is becoming serious concern for all around the world. As per medical evidences VDD is linked to the many diseases like hypertension, rheumatoid arthritis, muscle weakness etc. This paper elaborates the important of VDD, related diseases, awareness about nutritional foods, role of sun bathing and the standard recommended exposure limit by World Health Organization (WHO) for different geographical region and for different age group of people. All these facts were also discussed in context to India.

\section{K E Y W O R D S}

Vitamin D | Nutrient | Diseases

\section{I T A T I O N}

Sharma, Sheel (2018): Vitamin D - A Nutrient out to make its multifaceted presence felt. ESSENCE Int. J. Env. Rehab. Conserv. IX (1): 189-192. 
It does not sound short of alarm bells to the public health and nutrition professionals, that vitamin D deficiency (VDD) is assuming epidemic proportions in India and elsewhere cutting across different age groups, societal sections, life stages and regions. With the mounting evidence of VDD becoming linked to the pathogenesis and / or progression of several disorders including cancer, hypertension, multiple sclerosis, rheumatoid arthritis, osteoporosis, muscle weakness and diabetes mellitus; vitamin D is on the throes of becoming an emerging area of interest among researchers of basic and applied medical sciences, including those of health and nutrition the world over. Thus it is about time to accord contemporariness to the issue that it deserves in our native setting. The widespread deficiency of vitamin D merits adoption of policies that promote vitamin D status from deficient to adequate in masses. It is ironical that despite numerous reports of association of vitamin $\mathrm{D}$ with a spectrum of disease development, treatment and health maintenance, VDD is becoming widespread in occurrence. Originating in part from the diet but with a key source resulting from transformation by human exposure to sun shine, a great deal of the population suffers from VDD, especially owing to inadequate sun bathing. As a matter of fact, developing countries like India are experiencing a double disease burden of infections and non communicable diseases (NCD's) and revelations related to VDD and its health repercussions bode further ominous to the developing world. Lack of attention to the nutritional deficiency aspect as a key causative factor in the development of a disease makes the latter masquerade as a disorder of different origin causing people suffer for want of appropriate remedial action. The same can be the case with diseases lately attributed to VDD in relation to the revelations pertaining to the non- classical physiological role of vitamin $\mathrm{D}$. The ball can be set rolling by increasing the awareness among the nutritionists and health care professionals and, above all, in the general public, followed up by the drive to fortify Indian foods with vitamin $\mathrm{D}$ as a public health requirement.

As the facts coming to the fore point out that people of all age groups in several countries of the world are stricken with vitamin D deficiency, one finds but a few food options for vitamin D nutrition, its key source remains the human exposure to sunshine that transforms subcutaneous ( under the skin) precursor - 7-dehydrocholesterol to vitamin D3. Despite this natural bounty, a great deal of population suffers from VDD owing to inadequate sun exposure in tropics and scarce availability of sunlight in temperate regions of the globe. Numerous reports point towards VDD becoming widespread without any let or hindrance on one hand and pointing towards vitamin D deficiency and disease development association on the other. Taking steps aimed at increasing the public awareness pertaining to VDD and its health repercussions, facilitating VDD diagnosis, making people realize the importance of sun bathing and devising vitamin $\mathrm{D}$ intervention strategies that make food fortification with vitamin $\mathrm{D}$ as a means to combat this problem of immense health consequence.

As a matter of fact, VDD prevalence reports from across the continents point towards VDD as a global, untreated, unrecognized pandemic, rampant even in countries with abundant sunshine. Health implications of this vitamin have also assumed importance in the face of research findings that recognize non calcemic or pleiotropic effects (effects other than those pertaining to health and up keep of bones and teeth) of vitamin D as a potentially significant component of the biologic action of vitamin D. Active vitamin D metabolite in the body; $1,25(\mathrm{OH}) 2 \mathrm{D}$ (calcitriol), stimulates innate (macrophage; a white blood cell type, derived) immunity by enhancing bacterial killing on one hand to curve infections and modulates adaptive (lymphocyte; another white blood cell type, derived) immunity to minimize inflammation and thereby reduces the occurrence/ management of autoimmune disease on the other. According to a bevy of research reports, calcitriol acts on target genomic receptors in several organ systems to control proliferation, differentiation, genetic expression and cell signaling to keep diseases like cancer, hypertension, multiple sclerosis, rheumatoid arthritis, osteoporosis, muscle weakness and diabetes mellitus under leash. Diagnosing vitamin D insufficiency, a costly and expert based affair, needs to be made accessible to the masses accompanied by appropriate vitamin $\mathrm{D}$ intervention pro- 
grams and awareness strategies to raise vitamin D status to healthy levels.

Apart from exposure to sunlight, humans also get vitamin D through dietary intake. There are only a few foods which contain vitamin $\mathrm{D}$ such as fatty fish salmon, mackerel, and sardine, irradiated yeast, leafy vegetables and mushroom varieties. It has been reported that egg yolk also contain vitamin $\mathrm{D}$ in highly variable amounts but the sizeable cholesterol content of egg yolk with its adverse health repercussions makes it an impractical source of the vitamin. Other sources include mushrooms, portabella and shitake, raw or exposed to Ultra Violet - B light; alfalfa (Medicago sativa subspecies sativa) and lichen (Cladina arbuscula). To make up for inadequate dietary supply of vitamin D, some selective foods such as milk and milk products, juices, bread and breakfast cereals are also fortified with vitamin D. However, fortification as an option is not practiced in many developing countries including India. For intervention purposes, the industrial production of vitamin D3 (cholecalciferol) is made by irradiating 7-dehydrocholesterol with ultra violet-B (UVB) light followed by purification. The latter is a natural substance in wool grease (lanolin) harvested from sheep or other wool producing animals. Likewise, ergocalciferol (D2) is produced by using ergosterol from yeast or mushrooms as a precursor for irradiation with UVB light. As vitamin $\mathrm{D}$ is scarcely present in the foods consumed by the vast majority of people of the Indian sub-continent, they have to look for sunshine option as a plausible alternative. However, the pigmented dark skin of our people, which otherwise offers protection from deleterious effects of UV rays present in sunlight, goes to adversely affect their dermal efficiency for vitamin D synthesis from 7-dehydrocholesterol present in the layer under the skin. Likewise, low level of 7-dehydrocholesterol in the dermal layer (inner skin layer) of lean individuals, especially the malnourished children and elderly, is another reason that results in low 7- dehydrocholesterol to vitamin D3 output, despite prolonged sun exposure. In temperate regions, low intensity of sunlight hampers the skin option for vitamin D synthesis, especially in winter months. Thus climate, latitude and time of the day also dictate the efficiency of this mode of synthesis. Ozone layer, which absorbs UVB radiation above $290 \mathrm{~nm}$ wave length, is responsible for synthesis of vitamin D3. It is the density of ozone layer that decides the amount of UVB rays that can reach the earth. Thinner the ozone layer more would be the amount of D3 synthesized due to increased transmission of UVB. Zenith angle, the angle at which sunlight reaches the surface of earth is dictated by the thickness of ozone layer. Other factors that affect the zenith angle assumed no less importance in the synthesis of vitamin D through this option.

VDD is a significant public health problem in India despite abundant sunshine. It is highly prevalent across all age groups from earlier infancy to elderly.

Detection of Vitamin D deficiency- In the face of alarming prevalence of VDD, its status and cut offs have been most appropriately classified on the basis of serum $25(\mathrm{OH})$ D levels. It is important to mention here that diagnostic testing for VDD is no easy task as it involves analysis of serum $25(\mathrm{OH}) \mathrm{D}$ by radio-immuno assay (RIA) and related techniques which is a technical and costly affair and thus hardly accessible for common masses in developing countries.

Intervention Strategies- WHO expert committee 2004 recommends 200IU/day for adults with good to moderate sun exposure and 400IU/ day for those having sparse or no sun exposure. As per this Expert, Consultation committee, in countries falling near the equator (between latitudes $420 \mathrm{~N}$ and 420S), the most physiologically relevant and efficient way to acquire vitamin $\mathrm{D}$ by an uninterrupted 30 minutes skin exposure of the arms and face (without sunscreen) to sun. A disruption in sun exposure during this period annuls the whole process needing a fresh 30 minutes to start the process from scratch to completion. Since VDD is no less than an epidemic in many developed and developing countries, India being no exception despite sunshine in plentiful, its alleviation calls for vitamin $\mathrm{D}$ supplementation depending upon the severity of inadequacy. Among vitamins, vitamin $\mathrm{D}$ has turned out to be a multifaceted nutrient and health enhancer which has also become a missed out nutrient and seems out to make its presence felt through all round preva- 
er this homethruth is grasped the better.

\section{REFERENCES}

Calder, P. C. and Jackson, A. A. (2000): "Undernutrition, infection and immune function". Nutr Res Rev 13: 3-29.

Calder, P. C. and Kew, S. (2002): "The immune system: a target for functional foods" ? Br J Nutr 88: 165-177.

Cantorna, M. T. (2008): "Vitamin D and multiple sclerosis: an update". Nutr Rev 2008 66: 135-138.

Cantorna, M. T.; Munsick, C.; Bemiss, C. and Mahon, B.D. (2000): "1,25- Dihydroxycholecalciferol prevents and ameliorates symptoms of experimental murine inflammatory bowel disease". J Nutr 130: 26482652.

Cantorna, M. T.; Zhu, Y.; Froicu, M. and Wittke, A. (2004): "Vitamin D status, "1,25dihydroxy- vitamin D3, and the immune system". Am J Clin Nutr 80: 1717-1720.

DeLuca, H. F. (2004): "Overview of general physiologic features and functions of vitamin D". Am J Clin Nutr 80: 1689-1696.

DeLuca, H. F. and Cantorna, M. T. (2001): "Vitamin D: its role and uses in immunology". FASEB J 15: 2579-2585.

DeLuca, H. F. and Schnoes, H. K. (1983): "Vitamin D; recent advances". Annu Rev Bio-chem 52: 411-439.

Goswami, R.; Kochupillai, N.; Gupta, N.; Goswami, D.; Singh, N.; Dudha, A. (2008): "Presence of $25(\mathrm{OH})$ D deficiency in a rural North Indian village despite abundant sunshine". J Assoc Physicians India 56: 755-757.

Holick, M. F. (1990): “The use and interpretation of assays for vitamin D and its metabolites". J Nutr 120: 1464-1469.

Holick, M. F. (2004): "Vitamin D: importance in the prevention of cancers, type 1 diabetes, heart disease, and osteoporosis". Am J Clin Nutr 79: 362-371.

Holick, M. F. (2006a): "The role of vitamin D for bone health and fracture prevention". Curr Osteoporos Rep 4: 96-102.

Holick, M. F. (2006b): "Resurrection of vitamin D deficiencyand rickets". J Clin Invest 116:2062-2072.
Holick, M. F. (2007): “Vitamin D deficiency". N Engl J Med 357: 266-281.

Michael, F. (2007): "Vitamin D Deficiency". N Engl J Med 357: 266-281.

Michos., E. D., Melamed, M. L. (2008) Vitamin $\mathrm{D}$ and cardiovascular disease risk. Curr Opin Clin Nutr Metab Care 11: 7-12.

Puri, S., Marwaha, R. K., Agarwal, N., Tandon, N.,Agarwal, R., Grewal, K., Reddy, D.H., Singh, S. (2008) Vitamin D status of apparently healthy schoolgirls from two different socioeconomic strata in Delhi: relation to nutrition and lifestyle. Br J Nutr 99: 876-882.

Shivane, V. K., Sarathi, V., Bandgar, T., Menon, P., Shah, N.S. (2011) High prevalence of hypovitaminosis $\mathrm{D}$ in young healthy adults from the western part of India. Postgrad Med J 87: 514-518.

Zittermann, A. (2003) Vitamin D in preventive medicine: are we ignoring the evidence? Br J Nutr 89: 552-572.

Zittermann, A., Schleithoff, S. S., Koefer, R. (2005) Putting cardiovascular disease and vitamin D insufficiency into perspective. Br J Nutr 94: 483-492. 